\title{
TINGKAT SERANGAN HAMA PADA TANAMAN JABON (Anthocephalus cadamba Miq.) DI DESA NEGARA RATU II KECAMATAN NATAR KABUPATEN LAMPUNG SELATAN
}

\section{PEST ATTACKED LEVEL ON JABON PLANTATION (Anthocephalus cadamba Miq.) AT NEGARA RATU II VILLAGE NATAR DISTRICTS OF SOUTH LAMPUNG REGENCY}

\author{
Oleh/By: \\ Devi Yustia Safitri, Indriyanto, dan Agus M. Hariri \\ Jurusan Kehutanan Fakultas Pertanian Universitas Lampung \\ Jurusan Agroteknologi Fakultas Pertanian Universitas Lampung \\ J1. Soemantri Brojonegoro No. 1 Bandar Lampung \\ Email : dheadv9526@gmail.com \\ Phone : 081287760225
}

\begin{abstract}
ABSTRAK
Pohon jabon (Anthocephalus cadamba Miq.) di Indonesia merupakan salah satu jenis pohon yang dipilih untuk hutan tanaman. Kendala dalam pembangunan tanaman jabon adalah adanya berbagai jenis serangga yang menjadi hama tanaman tersebut. Penelitian ini bertujuan untuk mengetahui tingkat serangan tanaman jabon akibat serangan hama pada tanaman jabon di Desa Negara Ratu II, Kecamatan Natar, Kabupaten Lampung Selatan. Penelitian ini dilakukan pada bulan Juli sampai September 2015. Metode pengambilan sampel yang digunakan adalah petak ganda secara sistematis. Plot sampel yang digunakan berukuran $20 \mathrm{~m}$ x $20 \mathrm{~m}$, jarak antar plot dalam satu garis rintis $10 \mathrm{~m}$, sehingga jumlah plot sebanyak 18 plot. Adapun jenis hama yang diamati di setiap tegakan jabon adalah serangga yang menyerang dan gejala serangannya. Berdasarkan penelitian yang diamati, terdapat beberapa jenis serangga yang menjadi hama tanaman jabon, antara lain ulat kantong (Mahasena corbetti), belalang kembara (Locusta migratoria), wereng daun (Bothrogonia sp.), dan penggerek batang (Zeuzera sp.), yang menimbulkan serangan dengan kategori sedang dan rata - rata intensitas serangan sebesar 30,4\% $-62,4 \%$.
\end{abstract}

Kata kunci: hama, jabon, tingkat serangan

\begin{abstract}
Jabon (Anthocephalus cadamba Miq.) is one of the selected trees as plantation forest in Indonesia. The constrain of jabon plantation is various species of insects which become the pests. Therefore, this research was aimed to discover the damage level of jabon plantation the consequence of the pest attack on jabon forest in Negararatu II village, Natar district of South Lampung. This study was conducted from July to September 2015. The sampling method is systematically multiple plot. The plot size is $20 \mathrm{~m} \times 20 \mathrm{~m}$ and distance of each plots is $10 \mathrm{~m}$, hence the amount of the plots are 18. The result showed there were some insects species wich become the pest of jabon such as bagworm (Mahasena corbetti), grasshopper (Locusta migratoria), leafhopper (Bothrogonia sp.), and stem borer (Zeuzera sp.) that inflict damage level about 30,4\%-62,4\%.
\end{abstract}

Keywords: damage level, jabon, pest. 


\section{PENDAHULUAN}

Pohon jabon sebagai salah satu jenis tanaman alternatif untuk hutan tanaman yang ditanam untuk memenuhi kebutuhan rumah tangga. Kayu jabon memenuhi persyaratan tanaman sebagai bahan pulp dan kertas, sebab sifat pohonnya cepat tumbuh (fast growing), mempunyai serat kayu yang panjangnya $1,561 \mathrm{~m}$, diameter serat $23,95 \mathrm{~m}$, dan tebal dinding serat 2,78 $\mathrm{m}$ (Agri, 2011). Oleh karenanya potensi pemasaran kayu jabon cukup tinggi dan akan memiliki peran yang cukup penting pada masa yang akan datang, terutama jika pasokan kayu untuk pertukangan dan industri kehutanan dari hutan alam mulai menurun (Pratiwi, 2003). Namun demikian, sebagai suatu ekosistem hutan yang monokultur jabon rentan terhadap serangan hama terutama jika serangan hama tersebut terjadi sebagai akibat sedikitnya jumlah organisme predator. Disamping itu, pemeliharaan pohon jabon ada beberapa kendala yakni seperti serangan hama pada pohon jabon tersebut. Beberapa kelemahan tersebut dapat mengurangi kualitas serta kuantitas kayu pada tegakan hutan jabon. Hama yang menyerang suatu populasi hutan tanaman dapat bersifat sangat merusak.

Beberapa jenis hama telah diketahui menyerang tanaman jabon seperti ulat Daphnis hyphotous, Anthrocistra hilalaris (Warisno dan Dahana, 2002) serta Margaronia sp. dan uret (Krisnawati et al., 2011). Sehubungan dengan itu, perlu diadakanya penelitian mengenai seberapa besar tingkat serangan hama di Desa Negara Ratu II Kecamatan Natar Kabupaten Lampung Selatan guna mengoptimalkan pengetahuan tentang adanya serangan dari hama tersebut. Adapun tujuan penelitian ini adalah untuk mengetahui tingkat serangan hama pada hutan tanaman jabon di Desa Negara Ratu II Kecamatan Natar Kabupaten Lampung Selatan.

\section{METODE PENELITIAN}

Lokasi Penelitian dilaksanakan pada bulan Juli sampai dengan September 2015 pada lahan hutan seluas 2,83 ha. Lokasi penelitian terletak di lahan hutan milik warga di Desa Negara Ratu II Kecamatan Natar, Kabupaten Lampung Selatan. Adapun bahan yang digunakan yaitu tegakan jabon berumur 4 tahun, dan alkohol 70\%. Alat yang digunakan dalam penelitian ini yaitu kaca pembesar, mikroskop, pinset, botol spesimen, sarung tangan, tally sheet atau tabel nama, kamera digital, alat tulis, dan lembar pengamatan. Jenis data yang yang dikumpulkan dalam penelitian ini adalah data primer dan data sekunder. Data primer diperoleh langsung di lapangan dengan menggunakan tally sheet. Data primer yang diambil adalah hama yang ada di tegakan pohon jabon (Anthocephalus cadamba Miq.). Data sekunder adalah data yang sifatnya mendukung data primer, diperoleh melalui studi literatur, hasil penelitian terdahulu, dan informasi dari pemilik lokasi penelitian.

Intensitas sampling ( IS ) sebesar 25\%, pada luas lokasi 2,83 ha, maka jumlah plot sampel dalam penelitian ini ditentukan sebagai berikut.

$$
\mathrm{IS}=\frac{\mathrm{ll} \mathrm{s} \quad \mathrm{p} \quad \mathrm{si}}{\mathrm{ll} \quad \mathrm{ll}} \times 100 \%
$$

Luas seluruh plot sampel $\quad=$ IS $\times$ Luas lokasi

$$
\begin{aligned}
& =25 \% \times 2,83 \text { ha } \\
& =7075 \mathrm{~m}^{2}
\end{aligned}
$$




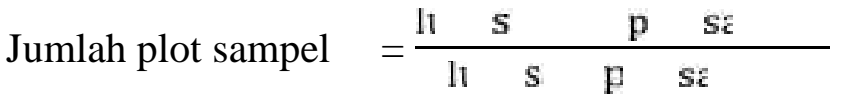

$$
\begin{aligned}
& =\frac{7 \quad \mathrm{II}^{2}}{4 \cdot \mathrm{II}^{2}} \\
& =17,68=18 \text { buah }
\end{aligned}
$$

Berdasarkan perhitungan tersebut maka banyaknya plot sampel yang harus dibuat adalah sebanyak 18 plot. Tanaman-tanaman sampel tersebut berada pada plot-plot yang berukuran $20 \mathrm{~m}$ x $20 \mathrm{~m}$ dengan jarak antar garis rintis $10 \mathrm{~m}$. Kejadian serangan hama dihitung menggunakan rumus berikut (Tulung, 2000 dalam Pribadi 2010).

$$
K=\frac{\mathrm{n}}{\mathrm{N}} \mathrm{x} 100 \%
$$

Keterangan:

$\mathrm{K}=$ kejadian serangan oleh hama tertentu;

$\mathrm{n}$ = jumlah tanaman yang terserang hama tertentu;

$\mathrm{N}=$ jumlah tanaman yang diamati dalam satu plot.

Perhitungan intensitas serangan oleh hama dihitung menggunakan rumus berikut (Direktorat Perlindungan Tanaman, 2000).

$$
\mathrm{I}=\frac{\sum \mathrm{n}_{\mathrm{l}} \cdot \mathrm{v}_{\mathrm{l}}}{\mathrm{N} \cdot \mathrm{V}} \times 100 \%
$$

Keterangan:

I = Intensitas serangan;

$\mathrm{n}_{\mathrm{i}} \quad=$ jumlah tanaman rusak (terserang hama) pada tingkat skor serangan tertentu;

$\mathrm{v}_{\mathrm{i}}=$ nilai skor serangan tanaman oleh serangan hama;

$\mathrm{i}=0,1,2,3,4,5$

$\mathrm{N}=$ jumlah tanaman yang diamati;

$\mathrm{V}=$ skor tertinggi kategori serangan hama.

Adapun skor serangan tanaman oleh serangan hama yang digunakan adalah:

Skor $0=$ Tidak ada serangan

Skor $1=$ Serangan sangat ringan (persentase organ yang terserang $1-20 \%$ );

Skor $2=$ Serangan ringan (persentase organ tanaman yang terserang $21-40 \%$ );

Skor $3=$ Serangan sedang (persentase organ tanaman yang terserang $41-60 \%$ );

Skor $4=$ Serangan berat (persentase organ tanaman yang terserang $61-80 \%$ );

Skor $5=$ Serangan sangat berat (persentase organ tanaman yang terserang $81-100 \%$ ).

\section{HASIL DAN PEMBAHASAN}

\section{A. Kejadian Serangan}

Hasil pengamatan menunjukkan bahwa secara umum hutan tanaman jabon di Desa Negara Ratu II Kecamatan Natar, Kabupaten Lampung Selatan pada kondisi baik, dengan pertumbuhan mencapai ketinggian rata-rata lebih dari $4 \mathrm{~m}$ (pada Gambar 1). Namun tanaman jabon tersebut tidak terlepas dari gejala serangan hama. Sebagaimana halnya jenis tanaman tahunan yang lain, tidak dapat terhindar dari gejala kerusakan oleh serangan hama. Gejala kerusakan yang paling jelas teramati ialah yang berupa kerusakan pada daun (Gambar 2). 


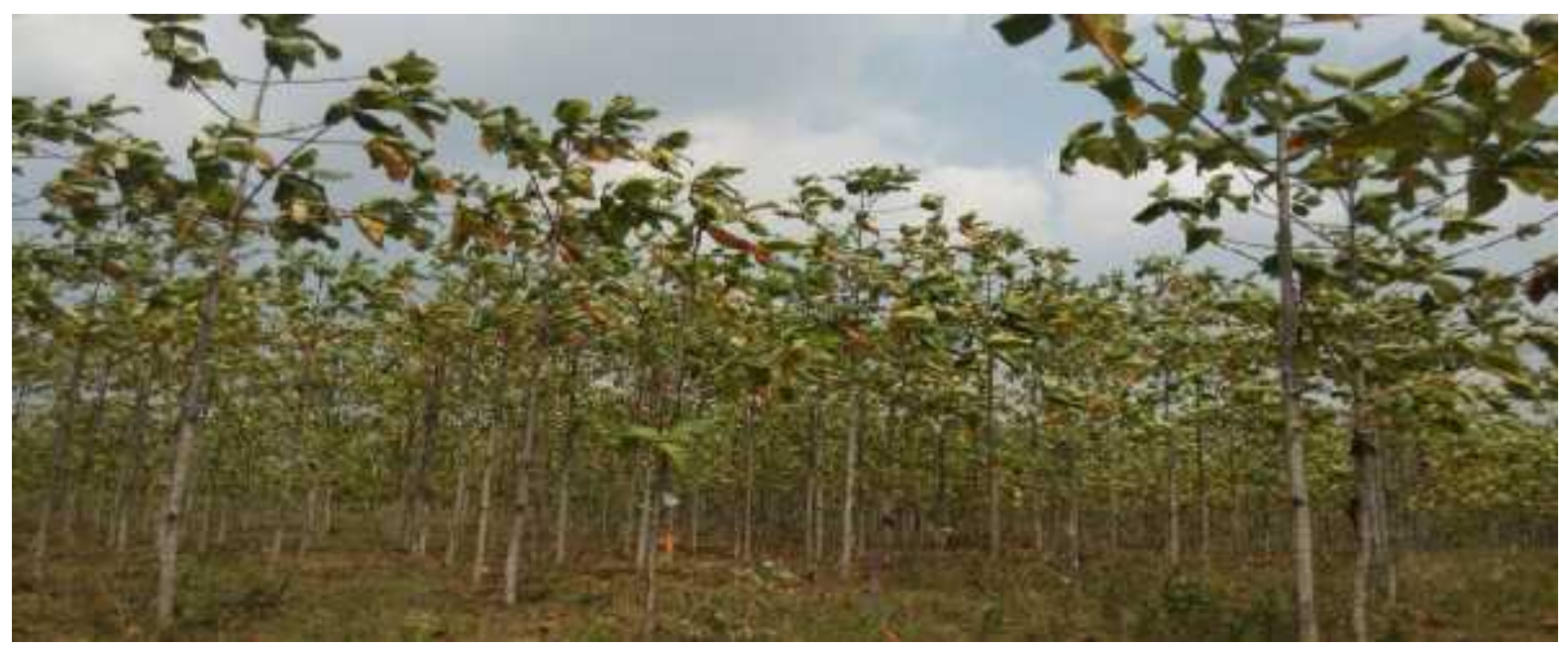

Gambar 1. Hutan tanaman jabon di Desa Negara Ratu II Kecamatan Natar, Kabupaten Lampung Selatan (Foto: Safitri, 2015).
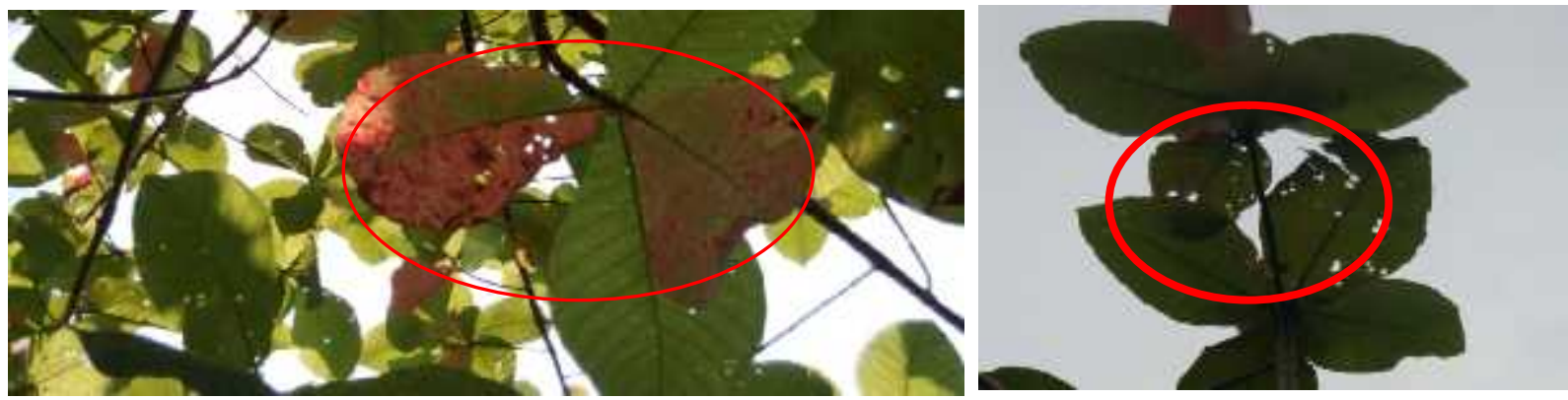

Gambar 2. Gejala kerusakan pada daun tanaman jabon (Foto: Safitri, 2015)

Serangan pada daun merupakan gejala gabungan dari serangan beberapa jenis hama sekaligus, salah satunya disebabkan oleh ulat kantong (Mahasena cobetti). Selain itu penelitian ini berlangsung pada musim kemarau (Juli sampai dengan September 2015) menyebabkan relatif tidak adanya pemulihan dari daun baru yang terbentuk.

\section{B. Intensitas Serangan}

Gejala serangan tanaman oleh serangan hama yang teramati dalam penelitian ini didominasi oleh serangan pada daun, yang pada umumnya disebabkan oleh serangga dengan tipe mulut mandibulata. Serangannya berupa daun-daun berlubang oleh aktivitas menggigitmengunyah serangga, baik lubang gigitan pada tengah daun maupun tepi helai daun.

Gejala serangan berupa daun berlubang umumnya dinilai sebagai serangan relatif. Maksudnya adalah daun yang mengalami serangan berat (lubang-lubang lebih banyak) akan diberi nilai serangan yang lebih tinggi, dari pada daun yang mengalami serangan ringan (lubang-lubang sedikit) didasarkan pada nilai skala serangan tersebut. Besarnya serangan dinyatakan sebagai intensitas serangan. Pada penelitian ini, intensitas serangan hama pada daun tegakan jabon diamati dan dihitung dari 5 sampel pohon per plot. Besarnya intensitas dari serangan masing-masing plot selama 8 minggu pengamatan disajikan pada Tabel 1 . 
Tabel 1. Intensitas serangan hama pada daun tanaman jabon di hutan tanaman jabon Desa Negara Ratu II Kecamatan Natar, Kabupaten Lampung Selatan.

\begin{tabular}{ccccccccc}
\hline & \multicolumn{7}{c}{ Intensitas serangan pada Minggu ke- $(\boldsymbol{\%})$} \\
\cline { 2 - 9 } & $\mathbf{1}$ & $\mathbf{2}$ & $\mathbf{3}$ & $\mathbf{4}$ & $\mathbf{5}$ & $\mathbf{6}$ & $\mathbf{7}$ & $\mathbf{8}$ \\
\hline 1 & 24 & 24 & 24 & 40 & 40 & 44 & 60 & 60 \\
2 & 24 & 24 & 24 & 40 & 40 & 40 & 48 & 48 \\
3 & 20 & 20 & 20 & 40 & 40 & 40 & 44 & 44 \\
4 & 28 & 28 & 28 & 52 & 52 & 52 & 52 & 52 \\
5 & 20 & 20 & 20 & 48 & 48 & 48 & 56 & 56 \\
6 & 24 & 24 & 24 & 40 & 40 & 40 & 52 & 52 \\
7 & 20 & 20 & 20 & 48 & 48 & 56 & 60 & 60 \\
8 & 28 & 28 & 28 & 40 & 40 & 40 & 60 & 60 \\
9 & 20 & 20 & 20 & 48 & 48 & 52 & 60 & 60 \\
10 & 20 & 20 & 20 & 40 & 40 & 40 & 60 & 60 \\
11 & 40 & 40 & 40 & 48 & 48 & 48 & 68 & 68 \\
12 & 40 & 40 & 40 & 56 & 56 & 56 & 68 & 68 \\
13 & 40 & 40 & 40 & 44 & 44 & 44 & 68 & 68 \\
14 & 40 & 40 & 40 & 52 & 52 & 52 & 64 & 64 \\
15 & 40 & 40 & 40 & 48 & 48 & 48 & 60 & 60 \\
16 & 40 & 40 & 40 & 52 & 52 & 52 & 68 & 68 \\
17 & 40 & 40 & 40 & 44 & 44 & 44 & 88 & 88 \\
18 & 40 & 40 & 40 & 56 & 56 & 56 & 88 & 88 \\
\hline Rata-rata & 30,4 & 30,4 & 30,4 & 46,4 & 46,4 & 47,4 & 62,4 & 62,4 \\
Intensitas & & & & & & & & \\
Serangan & & & & & & & & \\
Pada Daun & & & & & & & &
\end{tabular}

Berdasarkan Tabel 1 dapat diketahui bahwa tingkat serangan hama pada tanaman jabon dalam minggu ke-1 sampai ke-3 masuk dalam kategori ringan (30,4\%), minggu ke-4 sampai minggu ke-6 masuk dalam kategori sedang (47,4\%), minggu ke-7 sampai minggu ke-8 masuk dalam kategori berat $(62,4 \%)$.

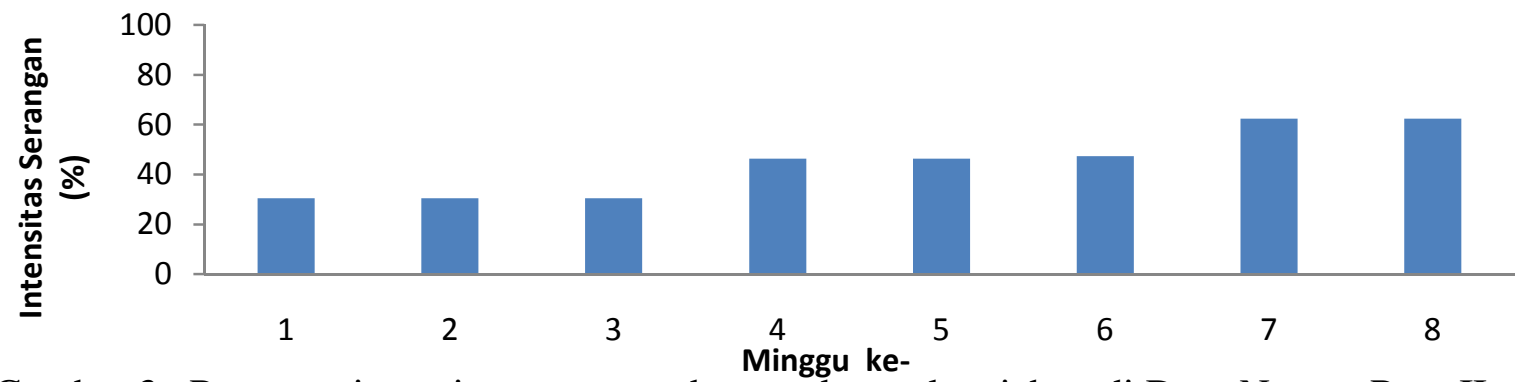

Gambar 3. Rata-rata intensitas serangan daun pada tegakan jabon di Desa Negara Ratu II Kecamatan Natar Lampung Selatan.

Hal ini menunjukkan adanya gejala serangan pada daun rata-rata pada tingkat serangan sedang (47,4\%). Periode penelitian yang berlangsung pada Juli sampai dengan September bertepatan dengan musim kemarau, menyebabkan serangan hama pemakan daun. Anggraeni (2012) menyebutkan bahwa hasil penelitian pada hutan rakyat tanaman jabon di Pantai Cermin Kabupaten Kampar, Provinsi Riau tampak serangan ulat daun (Arthroschista hilaralis) berkorelasi positif dengan temperatur atau cuaca panas. 
Menurut Subyanto (2000), biologi dan serangan serangga hama sangat erat dipengaruhi oleh faktor-faktor iklim dan cuaca seperti temperatur dan kelembaban, yang berkaitan dengan pergiliran musim hujan dan kemarau. Hama belalang kayu (Valanga nigricornis) yang sering menyerang tanaman akasia bertelur pada akhir musim hujan atau awal musim kemarau, kemudian menetas dan berkembang menjadi dewasa pada musim hujan berikutnya. Sebelum musim hujan berakhir, belalang betina dewasa bertelur lagi di dalam tanah dan telur tersebut akan tetap dorman (diapause) selama musim kemarau. Dengan demikian dijumpai adanya hama belalang kayu pada musim hujan sampai permulaan musim kemarau. Sedangkan hama Xyleborus destruens menyerang pohon jati yang tumbuh di daerahdaerah berketinggian di atas $500 \mathrm{~m}$ dpl dan relatif basah atau bercurah hujan $>2000 \mathrm{~mm}$.

\section{Hama-hama yang Menyerang Daun}

Menurut Chung et al. (2009), berdasarkan penelitian pada hutan tanaman jabon di wilayah Sabah Timur pulau Kalimantan diketahui bahwa hama daun yang paling dominan merusak tanaman jabon ialah ulat Arthroschista hilaralis (Lepidoptera: Pyralidae), dan hama berikutnya adalah ulat Daphnis hypothous (Lepidoptera: Sphingidae), serta beberapa jenis ulat kantong (Lepidoptera: Psychidae). Sedangkan yang tergolong perusak sedang (moderate) ialah ulat jengkal Antitrygodes divisaria (Lepidoptera: Geometridae), kumbang moncong Hypomeces squamosus (Coleoptera: Curculionidae), serta jengkerik pohon Nisitrus vittatus (Orthoptera: Gryllidae).

Hasil pengamatan Pribadi (2010) pada hutan tanaman industri (HTI) di sektor Pelalawan dan Baserah, serta hutan rakyat di Pantai Cermin, ketiganya di Provinsi Riau, memperoleh data bahwa hama-hama perusak daun pada tanaman jabon ialah ulat Arthroschista hilaralis, Daphnis hypothous dan ulat kantong, serta kepik Cosmoleptrus sumatranus (Hemiptera: Alydidae).

Adapun pada penelitian di lokasi hutan rakyat tanaman jabon di Desa Negara Ratu II Natar Lampung Selatan telah mendapatkan 3 jenis hama perusak daun, yaitu ulat kantong (Mahasena corbetti), belalang kembara (Locusta migratoria), dan jenis wereng daun (Bothrogonia sp.) (Gambar 4).

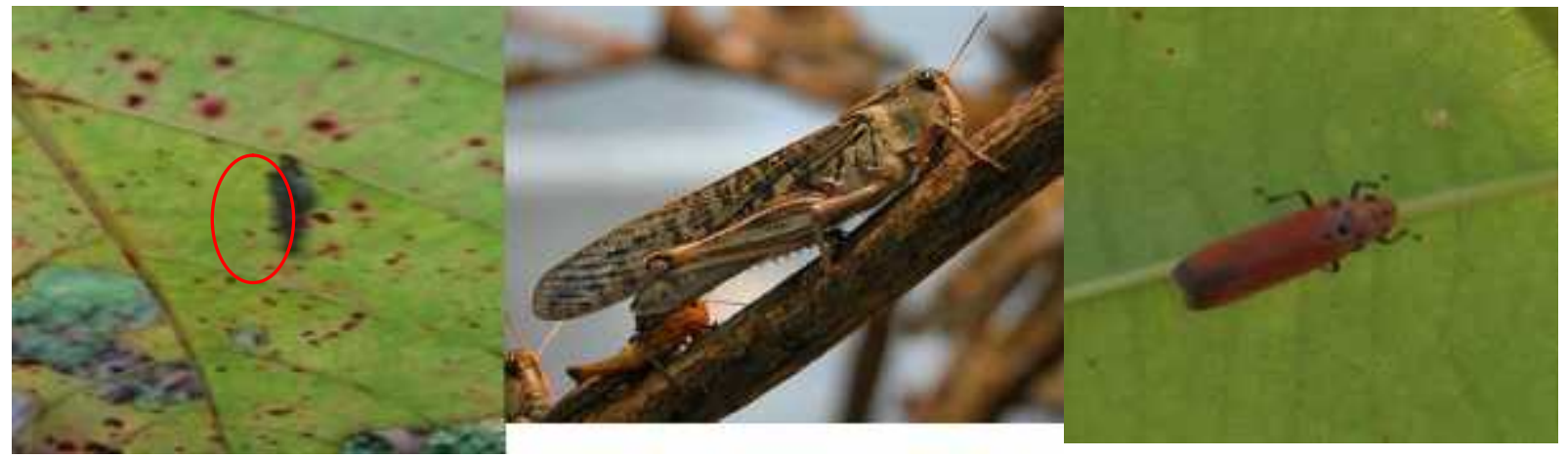

Gambar 4. Ulat kantong (Mahasena corbetti); belalang kembara (Locusta migratoria); dan wereng daun (Bothrogonia sp.) (berturut-turut dari kiri ke kanan) (Foto: Safitri, 2015)

Menurut Nair dan Sumardi (2000) Mahasena corbetti (Lepidoptera: Psychidae) adalah salah satu spesies dari ulat kantong (bag worm). Beberapa spesies ulat kantong lainnya adalah Clania lewinii, Clania ignobilis, dan Pteroma plagiophleps. Ciri khas ulat kantong ialah fase larva nya berupa ulat yang hidup di dalam sebuah pelindung serupa kantong yang berasal dari 
potongan-potongan daun maupun tangkai atau bagian-bagian bunga dari tanaman yang diserangnya. Ujung kantong adalah bagian dari ekor (posterior) ulat, sedangkan pangkal kantong adalah bagian anterior tempat lubang munculnya kepala ulat untuk aktivitas makan, bergerak dan menempelnya ulat pada daun atau bagian tanaman yang diserangnya.

Seekor ngengat $M$. corbetti betina mampu menghasilkan telur $2.000-3.000$ butir. Dalam waktu sekitar 16 hari telur menetas. Larva yang baru muncul sangat aktif dan bergantungan dengan benang-benang yang berasal dari air liurnya, sehingga mudah menyebar dengan bantuan angin, terbawa manusia atau binatang. Ulat sangat aktif makan sambil membuat kantong dari potongan-potongan daun. Ulat bergerak dan makan dengan hanya mengeluarkan kepala dan kaki depannya dari dalam kantong. Ulat awalnya berada pada permukaan atas daun tetapi setelah kantong semakin besar akan berpindah dan menggantung di bagian permukaan bawah daun. Pada akhir perkembangannya, panjang ulat dapat mencapai $30-50 \mathrm{~mm}$, dan selanjutnya akan memasuki fase kepompong tetap berada di dalam kantong selama lebih kurang 30 hari.

M. corbetti dikenal banyak menyerang tanaman kelapa dan kelapa sawit. Jika terjadi serangan ulat kantong yang parah maka tajuk tanaman tampak kering seperti terbakar. Tanaman pada semua umur rentan terhadap serangan ulat kantong, bahkan serangan bisa terjadi lebih berat pada tanaman yang lebih tua. Keadaan ini mungkin ditimbulkan dari kemudahan penyebaran ulat kantong pada tanaman yang lebih tua karena antar cabang atau ranting saling bersinggungan.

Jenis-jenis ulat kantong lainnya juga diketahui sebagai perusak daun (defoliator) pada sejumlah tanaman keras seperti kakao, mangga, dan jambu mete. Sedangkan ulat kantong Pteroma plagiophleps tercatat sebagai hama daun yang menimbulkan serangan besar pada Acacia mangium, sengon, dan jenis-jenis tanaman mangrove.

Menurut Nair dan Sumardi (2000) Locusta migratoria (Orthoptera: Acrididae) atau yang dikenal dengan nama umum belalang kembara diketahui sebagai jenis belalang yang persebarannya sangat luas, baik di Asia, Afrika, bahkan hingga Australia dan Selandia Baru. 'Belalang dewasa jantan panjang tubuhnya 35-50 mm, sedangkan yang betina $45-55 \mathrm{~mm}$. Warna belalang kembara bervariasi sesuai umur dan fase gregarius (populasi tinggi dan cenderung berkelompok) ataukah fase soliter (populasi rendah dan cenderung tidak berkelompok). Nimfa gregarius berwarna kuning hingga oranye dengan bintik-bintik hitam, sedangkan nimfa soliter berwarna hijau atau coklat. Belalang dewasa gregarius berwarna kuning kecoklatan, sedangkan dewasa soliter berwarna coklat dengan berbagai tingkatan warna hijau tergantung pada warna vegetasi tempat belalang tersebut menyerang.

Belalang kembara fase gregarius aktif terbang pada siang hari dalam kelompokkelompok besar. Pada senja hari, kelompok belalang kembara hinggap pada suatu lokasi, biasanya untuk bertelur pada lahan-lahan kosong, berpasir, serta makan tanaman yang dihinggapinya. Setelah telur menetas, perkembangan belalang akan berlangsung 35-40 hari (yaitu 7-8 hari untuk setiap instar). Nimfa fase gregarius umumnya ada bersama kelompok pada hari-hari pertama setelah menetas. Nimfa instar ke-5 dapat bermigrasi mencapai 3 $\mathrm{km} /$ hari. Migrasi belalang dimulai sekitar 10 hari setelah bersayap. Populasi mulai terjadi dalam 2-4 minggu setelah bersayap dan dalam 2-3 minggu, dan belalang betina dewasa mulai bertelur. Setiap betina dapat menghasilkan 2-3 kelompok telur, yang berisi rata-rata 60-80 telur. Dengan struktur mulut yang bertipe mandibulata (menggigit mengunyah) belalang kembara menyerang tanaman-tanaman yang dihinggapinya. Puncak serangan belalang kembara di daerah Lampung pernah terjadi pada tahun 1998 yang mencapai luas 6.818 ha 
pada lahan padi dan jagung yang tersebar di 43 kecamatan dari 83 kecamatan yang ada di Lampung. Pada tanaman perkebunan, data dari Dinas Perkebunan Provinsi Lampung memperlihatkan bahwa serangan belalang pada tahun 1998 mencapai total luas serangan 9.213 ha dengan wilayah terparah pada lahan tebu PTPN di Sungkai Utara, Sungkai Selatan, dan Kotabumi (Sudarsono, Hasibuan, dan Swibawa, 2011). Satu spesies belalang yang dikenal dengan nama belalang kayu atau Valanga nigricornis yang secara taksonomi satu famili dengan belalang kembara yaitu famili Acrididae, selama ini telah diketahui sebagai salah satu hama perusak daun pada tegakan akasia dan jati.

Bothrogonia sp. (Hemiptera: Cicadellidae) adalah serangga yang tergolong dalam kelompok wereng daun (leafhoppers). Dengan struktur mulut tipe haustelata (menusuk mengisap) serangga ini menyerang dengan menghisap cairan tanaman, baik jenis tanaman rumputan, semak, maupun pohon. Spesies-spesies lain di dalam famili Cicadellidae ini misalnya wereng hijau Nephotettix virescens yang menyerang tanaman padi, Empoasca sp. sebagai hama pada tanaman kentang, terong, dan jenis kacang-kacangan. Jenis serangga penghisap cairan tanaman yang telah banyak diketahui sebagai hama tanaman kehutanan antara lain kepik Helopeltis theivora pada akasia dan eukaliptus, serta Lawana candida pada dipterokarp (Nair dan Sumardi, 2000). Sedangkan yang menyerang tanaman jabon adalah kepik Cosmoleptrus sumatranus (Pribadi, 2010).

\section{Gejala Serangan pada Batang}

Pada lokasi hutan tanaman jabon di Desa Negara Ratu II Natar Lampung Selatan diketahui terdapat gejala serangan pada batang yang mengindikasikan serangan hama penggerek batang (Zeuzera sp.) Indikasi serangan hama penggerek batang (Zeuzera sp.) dapat dilihat pada Gambar 5.

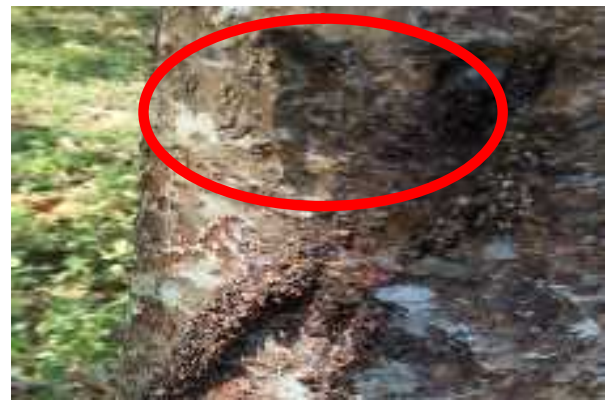

Gambar 5. Gejala serangan penggerek batang (Zeuzera sp.) pada batang jabon (Foto: Safitri, 2015)

Nair dan Sumardi (2000) menyatakan bahwa penggerek batang (Zeuzera sp.) adalah serangga yang tergolong dalam famili Cossidae ordo Lepidoptera. Fase pertumbuhan hama yang berperan sebagai perusak utama adalah ketika fase larva, yaitu berupa ulat dengan tipe mulut mandibulata atau menggigit mengunyah. Ulat Zeuzera sp. dapat menggerek batang pokok tanaman dan juga cabang sehingga menyebabkan tanaman mudah patah atau pertumbuhan tanaman menjadi terhambat. Pada serangan yang berat, hama ini dapat mengakibatkan kematian tanaman. Serangan hama ulat penggerek batang ini dapat diidentifikasi melalui adanya liang gerakan pada batang yang disertai butir-butir kotoran berwarna merah kehitam-hitaman yang keluar dari liang gerekan. Fase dewasa Zeuzera sp. adalah ngengat yang aktif pada malam hari 
dan dapat bertelur selama 6-8 kali sehari. Imago betina dapat memproduksi telur sebanyak 5001.000 butir selama masa hidupnya. Telur berwarna kuning kemerah-merahan dengan panjang 1 $\mathrm{mm}$ dan lebar 0,5 $\mathrm{mm}$ biasanya diletakan di celah kulit-kulit pohon.

Ulat berwarna merah cerah dengan panjang 3-5 $\mathrm{mm}$. Ulat tersebut dapat menggerek cabang dan batang tanaman hingga menyebabkan cabang atau batang yang terserang menjadi kopong dan menyisakan sedikit lapisan xilem dan floemnya saja. Ulat tersebut sering berpindah dari satu lubang gerekan ke bagian cabang lainnya untuk membuat gerekan baru. Liang gerekan bisa mencapai $40-50 \mathrm{~cm}$ dan diameter $1-1,2 \mathrm{~cm}$. Selain menyerang jabon, Zeuzera sp. juga dikenal sebagai hama pada eukaliptus, jati, mahoni dan juga pada bungur, randu, jambu biji, kopi, dan kina.

\section{SIMPULAN}

Berdasarkan penelitian yang diamati, terdapat beberapa jenis serangga yang menjadi hama tanaman jabon, antara lain ulat kantong (Mahasena corbetti), belalang kembara (Locusta migratoria), wereng daun (Bothrogonia sp.), dan penggerek batang (Zeuzera sp.), yang menimbulkan serangan dengan kategori sedang dan rata $\backslash$-rata intensitas serangan sebesar 30,4\%$62,4 \%$. 


\section{DAFTAR PUSTAKA}

Agri, F. 2011. Bisnis dan Budidaya Jabon Cepat Panen. Buku. Cahaya Atma Pustaka. Yogyakarta. $129 \mathrm{hlm}$.

Anggraeni, I. 2012. Penyakit karat tumor pada sengon dan hama cabuk lilin pada pinus di Jawa Barat. Jurnal Penelitian Hutan Tanaman 7(5):273-278 hlm.

Chung, A.Y.C., M. Ajik, R. Nilus, A. Hastie, R.C. Ong dan V.K. Chey. 2009. New records of insects associated with Laran (Neolamarckia cadamba) in Sabah. Sepilok Bulletin 10: 45-63 hlm.

Krisnawati, H., M. Kallio, dan M. Kanninen. 2011. Anthocephalus cadamba Miq.: Ekologi, Silvikultur dan Produktivitas. Buku. CIFOR. Bogor. 22 hlm.

Nair K.S.S. dan Sumardi. 2000. Insects Pest and Diseases in Indonesian Forest. Buku. CIFOR. Bogor. $87 \mathrm{hlm}$.

Pratiwi. 2003. Prospek pohon jabon untuk pengembangan hutan tanaman di Jakarta. Buletin Badan Litbang Kehutanan 4(1):61-66 hlm.

Pribadi, A. 2010. Serangan hama dan tingkat kerusakan daun akibat hama defoliator pada tegakan jabon (Anthocephalus cadamba Miq.) di Riau. Jurnal Hutan dan Konservasi Alam 7(4):451-458 hlm.

Sudarsono, H. , R. Hasibuan dan I G. Swibawa. 2011. Hubungan antara curah hujan dan luas serangan belalang kembara (Locusta migratoria manilensis Meyen) di Provinsi Lampung. Jurnal Hama Penyakit Tanaman Tropika 11(1): 95-101 hlm.

Subyanto. 2000. Ilmu Hama Hutan. Buku. Universitas Gajah Mada. Yogyakarta. 297 hlm.

Warisno dan K. Dahana. 2002. Peluang Inventasi Jabon Tanaman Kayu Masa Depan. Buku. Jakarta. PT. Gramedia Pustaka Utama. 109 hlm. 